\title{
Pesticide leaching in Danish groundwater: identification of vulnerable areas
}

\author{
Erik Nygaard, Vibeke Ernstsen, Carsten S. Jacobsen, Ole H. Jacobsen, René K. Juhler, \\ Peter van der Keur, Svend E. Olesen, Jim Rasmussen, Per Rosenberg and Henrik Vosgerau
}

In Denmark the supply of drinking water is based almost solely on groundwater. During the past few decades Danish groundwater monitoring has encountered numerous instances of pollution with pesticides and their metabolites (GEUS 2003a). As a result, some hundreds of abstraction wells out of about 8000 in general water supply have been closed. With this background, there is a particular concern for reducing the leaching of pesticides into the groundwater. In the present study an approach for identification of areas potentially prone to pesticide leaching is described.

The potential risk of leaching of pesticides from agricultural areas into groundwater is minimised through a procedure of approval; however, some leaching still occurs (GEUS 2003b). The Danish counties are therefore obliged to identify areas where there is a particular risk of pesticide leaching, and where restrictions in use of pesticides may be introduced to reduce the risk (Miljøstyrelsen 2000).

The Geological Survey of Denmark and Greenland (GEUS) and the Danish Institute of Agricultural Sciences (DJF) have carried out a project, focusing on sandy agricultural areas, that attempts to establish the necessary background knowledge for identifying areas particularly prone to pesticide leaching. The project aims to distinguish vulnerable and less vulnerable areas, both locally and nationwide, in a cost-effective way.

\section{Aim and approach}

The conditions under which pesticides leach from the ground surface into aquifers have been intensively investigated (e.g. Flury 1996; Worral et al. 2002). A general knowledge as to the circumstances and parameters that determine the fate of pesticides is thus already available. The objective of the project has been to establish a consistent set of data for Danish conditions, which will allow spatial comparison of pesticide leaching vulnerability on the basis of parameters that are known, or suspected to, influence leaching.

Since mapping is the key to the identification of vulnerable areas, emphasis has been placed on generating a set of data based on soil parameters that can be easily and relatively inexpensively obtained. For this purpose field sites have been chosen within eight areas of western Denmark (Jutland) with

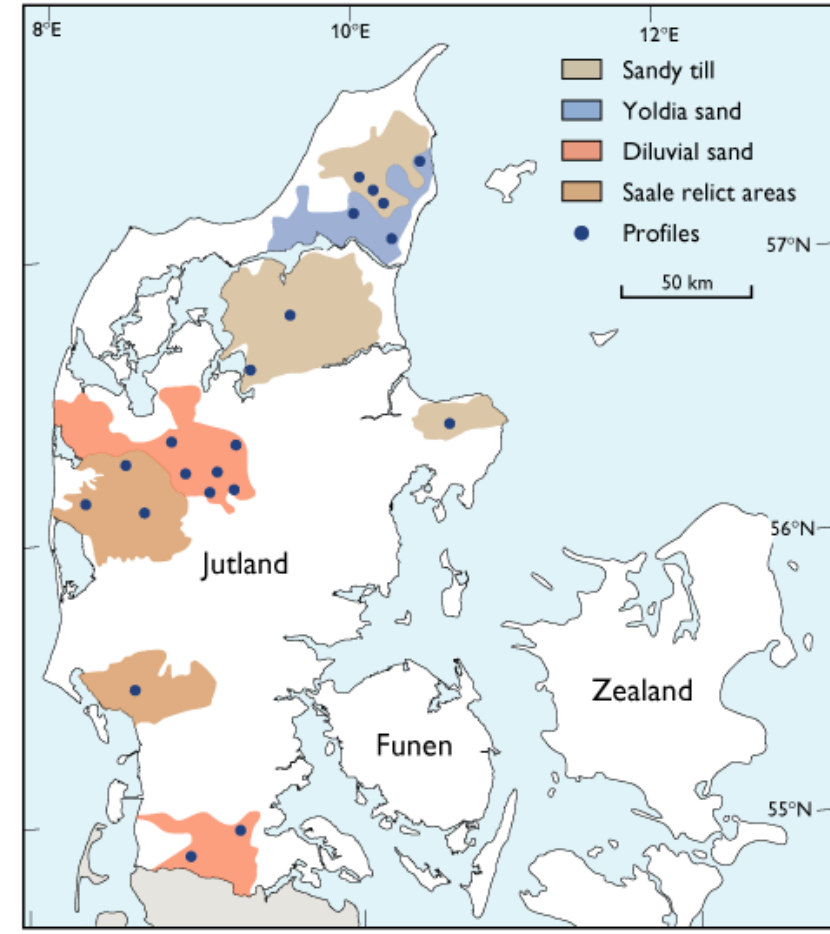

Fig. 1. Location of the studied field sites in Jutland, Denmark. The soil types of the eight selected areas are also shown.

different geological settings (Fig. 1). For each site, measuring of geological and pedological profiles have been carried out and samples collected for analysis.

To determine which areas are the most vulnerable to leaching, simulations have been carried out using the MACRO4.3 model (Jarvis 2002). The relationships between soil hydraulic properties, pesticide sorption (sensu e.g. Dubus et al. 2001) and disappearance (Beulke \& Brown 2001), and the more readily obtainable soil parameters (here termed 'inherent soil parameters'), have been investigated on the basis of data obtained from the field sites, pre-existing databases and the published literature.

Studies have aimed at determining the extent to which pesticides as a whole, or in characteristic groups, will leach under similar boundary conditions and reflect different combinations of inherent soil parameters. 


\section{Simulations}

The study of vulnerability to leaching is focused on criteria that are robust with respect to climatic variation and land use. All the field sites chosen were on pig farms, with normal crop rotation, farm manure application, and the relevant pesticides were applied to the maximum permitted. The pesticides MCPA, metribuzin and glyphosat, and methyltriazinamin, a transformation product of tribenuronmethyl, have been studied in most detail.

For glyphosat, sorption values and disappearance rates are so high that leaching could not be simulated.

Repeated model simulations (MonteCarlo type) for metribuzin indicated that leaching will occur at significant levels, while no leaching could be simulated for MCPA and methyltriazinamin (Fig. 2).

To illustrate the possible relationships, e.g. the hydraulic properties of the soil and the degree of leaching, eight different combinations of sorption and degradation properties of the topsoil and the lower soil were designed (Fig. 3). These combinations represent a wide range in properties for which the occurrence of leaching can be simulated. Such designed compounds are therefore suitable for further analysis. Keeping the sorption and disappearance parameters constant, the influence of hydraulic properties on leaching can also be studied (see below).

These simulations were undertaken for the sandy soil profiles stored in a DJF nationwide database (Fig. 2). The results indicate that maintaining the disappearance rate constant, the sorption properties of the topsoil will generally dictate the

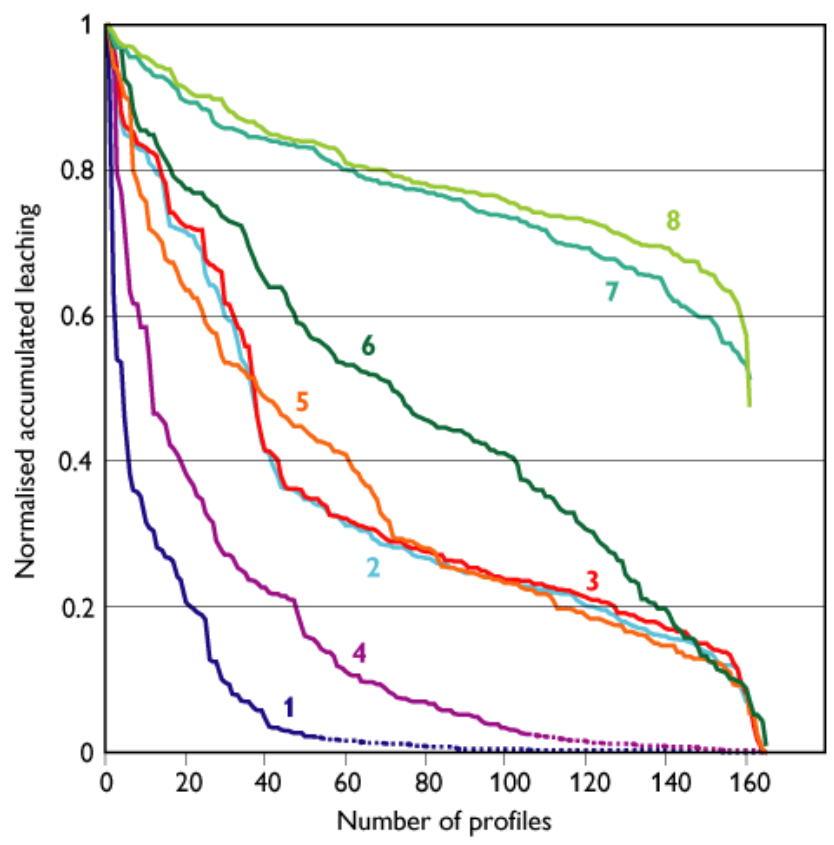

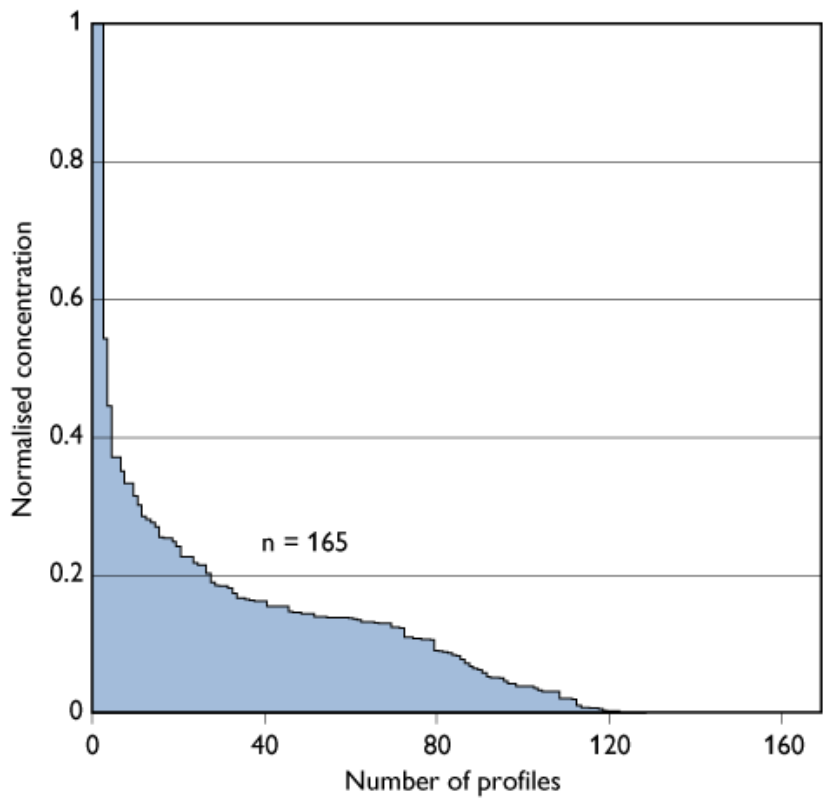

Fig. 2. Normalised concentration of metribuzin at a depth of $1 \mathrm{~m}$ in all sandy soil profiles stored in a national database held at DJF (one profile for every $50 \mathrm{~km}^{2}$ ).

level of leaching (Fig. 3). Cross-plots of the simulation results for the designed compounds further indicate, by their good correlation, that irrespective of the combination of designed parameters, leaching will dominantly occur in the same soil profiles (Fig. 4).

\begin{tabular}{ccccc}
$\begin{array}{c}\text { Compound } \\
\text { no. }\end{array}$ & $\mathrm{k}_{\text {topsoil }}$ & $\mathrm{k}_{\text {lower soil }}$ & $\mathrm{Kf}_{\text {topsoil }}$ & $\mathrm{Kf}_{\text {lower soil }}$ \\
\hline 1 & $1 \times 10^{-3}$ & 0 & 5 & 1 \\
2 & $1 \times 10^{-3}$ & $1 \times 10^{-3}$ & 5 & 0 \\
3 & $1 \times 10^{-3}$ & 0 & 5 & 0 \\
4 & $1 \times 10^{-2}$ & 0 & 1 & 1 \\
5 & $1 \times 10^{-2}$ & $1 \times 10^{-3}$ & 1 & 0 \\
6 & $1 \times 10^{-3}$ & 0 & 1 & 1 \\
7 & $1 \times 10^{-3}$ & $1 \times 10^{-3}$ & 1 & 0 \\
8 & $1 \times 10^{-3}$ & 0 & 1 & 0
\end{tabular}

Fig. 3. Number of investigated profiles ranked according to potential for leaching of eight designed combinations of pesticides. The ranking array of profiles is different for the eight curves; see also Fig. 4. 


\section{Correlation}

The input parameters for simulation (sorption, disappearance and hydraulic properties) are expensive to establish and therefore not viable for extensive or general mapping. Consequently, using a correlation analysis, an attempt has been carried out in order to substitute these parameters by more readily available soil parameters. The key inherent soil parameters evaluated are soil grain size distribution, soil bulk density, organic carbon content, cation exchange capacity, $\mathrm{pH}$, the content of oxalate and dithionit extractable iron and aluminium. Indicators of biological activity have also been evaluated (arylsulphatase activity and substrate induced respiration).

Two methods of correlation analysis have been applied to study the possible correlation between inherent soil properties, hydraulic properties and pesticide specific parameters: neural network computing and multivariate data analysis. Based on neural networking computing, soil water release curves have been estimated from hydraulic properties, and a satisfactory prediction of the soil-water release characteristics obtained (Fig. 5).

Measured values of sorption and disappearance rate have been correlated with the key inherent soil parameters by multivariate data analysis (Esbensen 2002). The sorption and disappearance values were predicted at the $85 \%$ level of variance for the investigated pesticides (Fig. 6).

The number of soil parameters required to obtain this correlation vary according to pesticide type. The content of organic carbon in the topsoil is generally the most important soil parameter, but other soil parameters such as $\mathrm{pH}$ and clay content were also important in some examples.

\section{Grouping of pesticides}

Extensive analyses have been carried out for a large group of pesticides at a few localities, in order to clarify whether the results with respect to the four intensely studied compounds can be applied to a broader group of pesticides. This has been investigated by correlation analysis between inherent soil properties and sorption for all the compounds. These investigations suggest that pesticides may be arbitrarily grouped in one or a few major groups, which have similar relationships to inherent soil parameters. The two compounds that do not correspond with the explanation (glyphosat and the metabolite 4 isopropyl aniline from isoproturon) are relatively strongly sorbing and degrading in sandy soils.

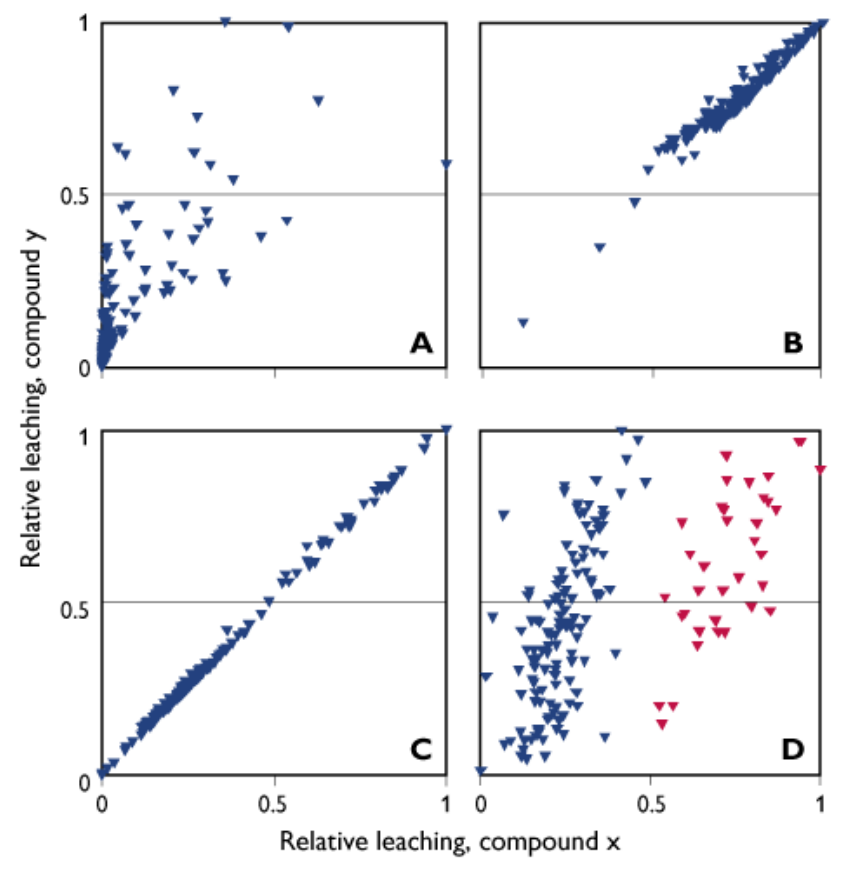

Fig. 4. Cross-plots of leaching of pairs of hypothetical pesticides in Fig. 3. The plots illustrate the extent to which the hypothetical pesticides leak through the same profiles. A: Low correspondence between profiles with the least leaking pesticides with high sorption in the topsoil and less in the lower soil. B: High correspondence between profiles with intermediate leaking pesticides with high sorption in the topsoil and none in the lower soil. C: High correspondence between profiles with the most leaking pesticides with low sorption in the topsoil and none in the lower soil. D: Two families of relatively high correspondence, where one profile has high sorption and low disappearance in the topsoil, and the other has low sorption and high disappearance in the topsoil.

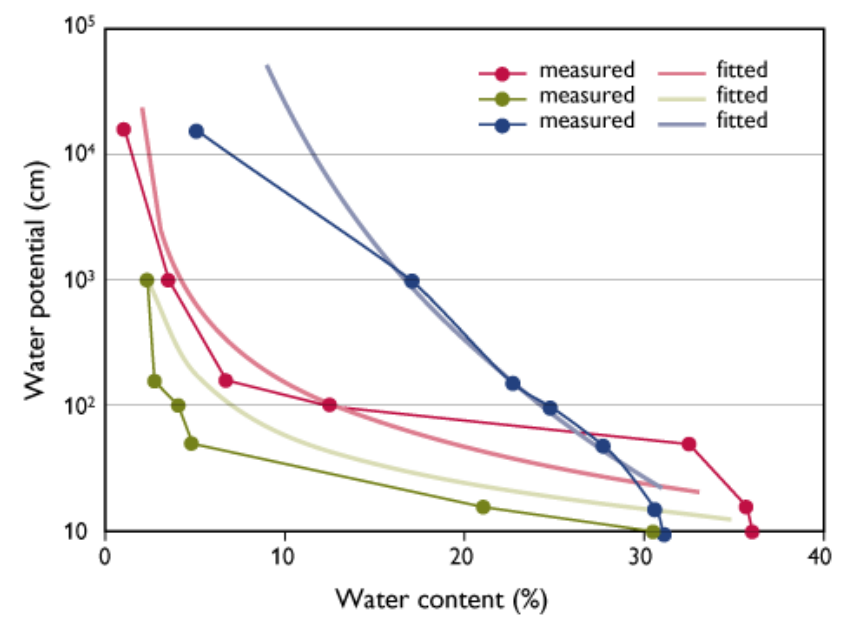

Fig. 5. Measured versus neural-network predicted retention curves for three of the investigated soil types. 


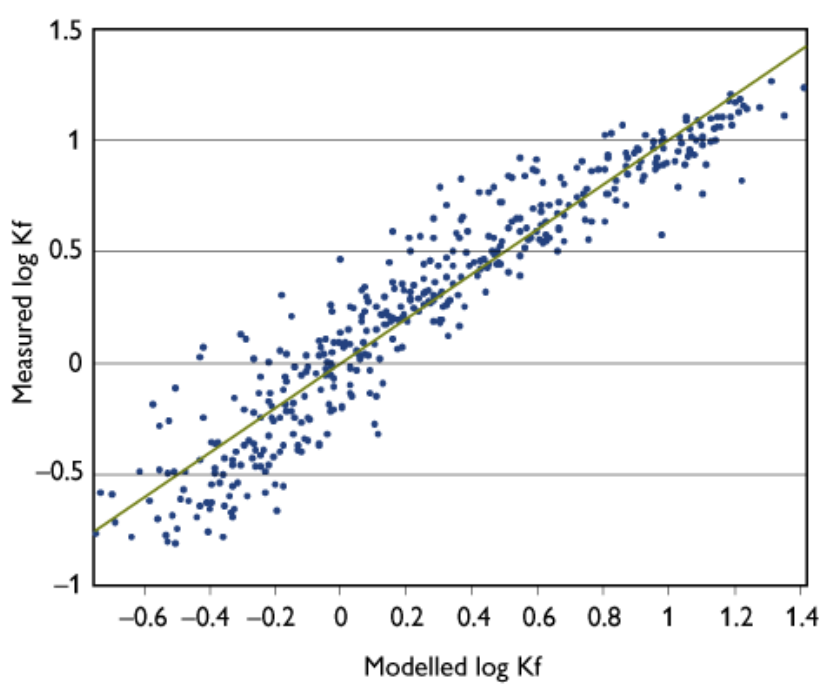

Fig. 6. Measured versus model-predicted sorption (Kf) for MCPA using multivariate data analysis.

\section{Delineation in practice}

Based on correlations of soil parameters and leaching, and grouping of pesticides, the values of soil and other parameters that may be useful for identifying soils where leaching may occur, have been investigated. Knowing the rank of importance of the soil parameters, and possibly their critical values, criteria have been established for a two-phase approach in mapping. It is suggested that, initially, areas with little risk of leaching may be identified and delineated based on the few most descriptive soil parameters. These parameters can to some extent be obtained from existing geographical data, and the cost of establishing new data is relatively low. The remaining areas particularly prone to leaching can be mapped on the basis of soil parameters necessary for simulating and predicting the leaching of the pesticides.

\section{References}

Beulke, S. \& Brown, C.D. 2001: Evaluation of methods to derive pesticide degradation parameters for regulatory modelling. Biology and Fertility of Soils 33(6), 558-564.

Dubus, I.G., Barriuso, E. \& Calvet, R. 2001: Sorption of weak organic acids in soils: clofencet, 2,4-D and salicylic acid. Chemosphere 45,767-774.

Esbensen, K.H. 2002: Multivariate data analysis in practice, 598 pp. Oslo, Norway: CAMO Process AS.

Flury, M. 1996: Experimental evidence of transport of pesticides through field soils: a review. Journal of Environmental Quality 25, 25-45.

GEUS 2003a: Grundvandsovervågning 2003, 110 pp. København, Danmark: Danmarks og Grønlands Geologiske Undersøgelse.

GEUS 2003b: The Danish pesticide leaching assessment programme, monitoring results, May 1999 to June 2002. Third report, 123 pp. Copenhagen, Denmark: Geological Survey of Denmark and Greenland, Danish Institute of Agricultural Sciences, National Environmental Research Institute.

Jarvis, N.J. 2002: The MACRO model (Version 4.3). Technical description. Available at: http://www.mv.slu.se/bgf/

Miljøstyrelsen 2000: Zonering. Vejledning 3, 156 pp. København, Danmark: Miljøstyrelsen.

Worral, F., Besien, T. \& Koplin, D.W. 2002: Groundwater vulnerability: interactions of chemicals and site properties. The Science of the Total Environment 299, 131-143.

\section{Authors' addresses}

E.N., V.E., C.S.J., R.K.J., P.v.d.K., J.R., P.R. \& H.V., Geological Survey of Denmark and Greenland, Øster Voldgade 10, DK-1350 Copenhagen K, Denmark. E-mail: en@geus.dk

O.H.J. \& S.E.O., Danish Institute of Agricultural Sciences, Blichers Allé, Postbox 50, 8830 Tjele, Denmark. 